University of Wollongong

Research Online

Faculty of Engineering and Information

Faculty of Engineering and Information

Sciences - Papers: Part A

Sciences

$1-1-2005$

\title{
Maximising voltage support in distribution systems by distributed generation
}

An D. T Le

University of Tasmania, dtale@utas.edu.au

Kashem M. Muttaqi

University of Tasmania, kashem@uow.edu.au

Michael Negnevitsky

University of Tasmania, michael.negnevitsky@utas.edu.au

Gerard Ledwich

Queensland University of Technology, g.ledwich@qut.edu.au

Follow this and additional works at: https://ro.uow.edu.au/eispapers

Part of the Engineering Commons, and the Science and Technology Studies Commons

Research Online is the open access institutional repository for the University of Wollongong. For further information contact the UOW Library: research-pubs@uow.edu.au 


\title{
Maximising voltage support in distribution systems by distributed generation
}

\begin{abstract}
Rapidly increasing in the demand of electricity along with recently advances in distributed generation (DG) technologies have sparked a new interest in utilisation of DG sources. However, there are a number of technical issues regarding to the installation of DG, since DG connection significantly affects existing network configuration and operation, especially for system with high level of DG penetration. To achieve maximum voltage support from DG utilisation, methodologies related to DG placement and DG operation are developed in this paper. Technique to optimise voltage improvement by effectively injecting active and reactive power of DG is developed based on voltage sensitivity of lines. An index has been developed to obtain optimal or near optimal placement of DG for maximum voltage improvement in a distribution feeder. Simulation studies are conducted on 16-bus, 32-bus and 69-bus radial test systems to verify the developed techniques and results are reported
\end{abstract}

\section{Keywords}

support, voltage, distribution, maximising, generation, systems, distributed

\section{Disciplines}

Engineering | Science and Technology Studies

\section{Publication Details}

A. D. T. Le, K. A. Kashem, M. Negnevitsky \& G. Ledwich, "Maximising voltage support in distribution systems by distributed generation," in IEEE Region 10 Annual Meeting (IEEE TENCON 2005), 2005, pp. 1-6. 


\section{Dynamics of a Hydro-Wind Hybrid Isolated Power System}

ARTICLE

Source: OAI

4 AUTHORS, INCLUDING:

Kashem M. Muttaqi

University of Wollongong

110 PUBLICATIONS 1,031 CITATIONS

SEE PROFILE

Michael Negnevitsky

University of Tasmania

195 PUBLICATIONS 2,023 CITATIONS

SEE PROFILE

\section{Gerard Ledwich}

Queensland University of Technology

418 PUBLICATIONS 3,484 CITATIONS

SEE PROFILE 


\section{Dynamics of a Hydro-Wind Hybrid Isolated Power System}

\author{
M. Aktarujjaman, M.A. Kashem, M. Negnevitsky \\ School of Engineering \\ University of Tasmania \\ Tasmania, Australia \\ $\underline{\text { mda00utas.edu.au }}$
}

\section{ABSTRACT}

Implementation of Distributed Generation (DG) can improve power quality and reliability, and guarantee continuity of power supply. This paper addresses the issue of continuity of power supply especially for isolated communities. A part of a network can be electrically isolated from the main grid when the grid fails to supply power due to a fault in the network or unavailability of power generation. In this paper, a mini hydro-wind hybrid power system is considered, and operation and control of the hybrid system during connecting it with the grid as well as its operation in the isolated condition are investigated. The system behaviour and DG responses are also examined. Islanding operation is the most sensitive and problematic operation in power systems. Simulation has been conducted with PSCAD/EMTDC on a hypothetical test system for different scenarios and results are presented.

Index terms-Distributed generation, islanding operation, wind turbine, mini-hydro, and hybrid system.

\section{INTRODUCTION}

Hybrid power systems are becoming very popular in rural and regional communities due to the lack of grid supplies. A hybrid system is a system where two or more small energy sources are integrated together to support customers in an area. It can operate with a grid system or independently as an isolated system. Hybrid system uses renewable or non-renewable energy resources to generate power. Recent developments in various smallscale generation technologies and government encouragements boost the utilisation of distributed generation (DG), and provide an opportunity to support rural and regional customers with hybrid power systems. Distributed generation can be defined as a small-scale generation, in the range of a few kilowatts to few megawatts, and situated close to consumers. Several types of DG technologies have already been developed and now commercially available such as photovoltaic, wind turbine, fuel cell, micro turbine, mini hydro.

Distributed generation with less emission technologies involved can also reduce environmental impact. The DG technology has been considered economical for rural or remote area customers [1]. Economical and environmental benefits influence customers as well as power utilities to utilise DG.

The main benefits of DG utilisation are [2]:) maintaining continuity of power supply to customers, enhancing

\author{
G. Ledwich \\ School of Engineering Systems \\ Queensland University of Technology \\ Brisbane, Australia
}

power quality and system reliability, supporting peak shaving, reducing power losses, deferring network expansion, and improving the total system capacity. DG can operate with the grid system to support the grid voltage or as an isolated system to support customers isolated from the grid. Islanding occurs when a portion of the distribution system becomes electrically isolated from the utility but with DG that sometimes to supply into the isolated system [3]. An islanding situation may occur as a deliberate state of operation or as an unintended outcome. The island can be characterised as being either generation poor or generation rich. Generation under supply leads to under frequency and under voltage problems in the islanded system whereas generation rich or generation over supply can lead to over frequency and over voltage issues [4]. An over generated islanded system can be stabilised by governor system; the stabilisation under under-generation requires special planning and usually dependent on a load shedding scheme. The control strategy of DG should be designed so that DG can support a stable islanded system and help to prevent the total black out of the system.

In this paper, a mini hydro-wind hybrid system is investigated for operation with a grid system as well as the islanded conditions. Following scenarios are considered: behaviour of the grid connected hybrid system during disturbances; control actions of the hybrid system during the process of forming an island and after the island is formed; and stability of the isolated hybrid system. Simulations are conducted on a simple system for each of the above scenarios.

\section{ISLANDING OVERVIEW AND CONTROL REQUIREMENT}

Islanding operation is often required for continuous power supply in rural or regional areas, where blackouts may occur frequently. Unintentional islanding may occur due to large system disturbances such as faults, loss of main generation. Intentional islanding is usually planned earlier and undergoes through a sequence of predefined actions. Unintentional islanding may also introduce some safety hazards [5], so proper safety procedures are required. Fast and reliable islanding detection techniques ensure successful islanding operations [6]. For a satisfactory islanding operation, control strategies should be designed taking into account over generation and under generation issues. The load-generation mismatch is a key issue for an islanding operation.

Stable operation of a hybrid system depends on continuous matching the load and generation, as well as reactive power control strategies [7]. During 
disturbances, the normal states of the network and network parameters are changed. Therefore, a hybrid system requires new control strategies to adapt to new conditions.

To develop an adequate control strategy of hybrid generation units for the isolated operation, dynamic and transient stability studies are needed. The delivery of electric power by the DG can be determined as [7]:

$$
P_{e}=\frac{E V}{X} \sin \delta
$$

where, $\mathrm{P}_{\mathrm{e}}$ is the power transfer, $E$ is the generator voltage, $V$ is the grid voltage, $X$ is the reactace between the grid and the generator, and $\delta$ is the angle between the generator voltage and the grid voltage. Therefore, the power transfer depends on the DG voltage, grid voltage, line reactance, and power angle. A disturbance changes voltage and reactace parameters of the system and alter the power transfer. For example, opening a circuit breaker increases the reactance value while a short circuit decreases the reactance value and also the voltage level [8].

If a disturbance occurs in a system, the system will immediately notice a power mismatch or unbalance which can be expressed by the following equation.

$$
P_{u}=P_{m}-P_{e}
$$

where, $P_{m}$ is the mechanical power produced by prime mover, $P_{e}$ is the electrical power produced by the generator and delivered to the load, and $P_{u}$ is the unbalnced power followed by the disturbance. As mentioned above, the electric power $\mathrm{P}_{\mathrm{e}}$ changes due to a disturbance. As a result, the mechanical power $P_{m}$ is no longer equal to the electrical power $P_{e}$ required by the load. The unbalaced power $P_{u}$ needs to be absorbed or provided by the generator rotor causing increasing or decreasing its angular velocity before generator control action take place $[7,8]$. This could result the instability of the system. Large generation systems have appropriate controllers to take actions before the system crosses the stability limit. If a disturbance cannot be kept under control, then protection systems isolate the affected portion of the systems which can create an option for the islanding operation if a DG is involved. An islanded system usually contains one or several DG(s) which can be operated with or without the grid connection. The DG control system is usually designed to operate in parallel with the grid and stabilise the system during the islanding process and after the island is formed. When an islanding occurs, the DG contol should response according to the system requirement.

\section{MODELLING THE HYBRID SYSTEM}

A hybrid system to be modelled has two renewable energy resources, the wind turbine and the mini-hydro. The hybrid system is capable of supporting total load of the area and also exporting power to the grid. The system is operated on the voltage control mode when it is connected with the grid and on the frequency control mode when it becomes islanded. The size of wind turbine is smaller than the size of mini-hydro and is not capable of supporting the total system demand alone. Mini-hydro unit is performing voltage and frequency controls through the exciter and governor system. The hydro exciter keeps the islanded system voltage within the acceptable level and the governor responses according to the load-generation mismatch. A careful selection of the governor parameters can produce a stable and satisfactory operation of islanded system and respond according to load changes [8].

Fig.1 shows a typical model of a hybrid power system consisting of a mini-hydro turbine, DG1, a wind generator, DG2, and loads connected using the medium voltage (MV) grid. The governor system normally measures system frequency and controls generation. In the voltage support mode, the generation level may be adjusted based on the system voltage. The desired level of voltage can be achieved through the exciter control. Combination of the governor and exciter system of DG1 needs to be designed to provide a stable and satisfactory islanding operation as well as a parallel operation with the grid.

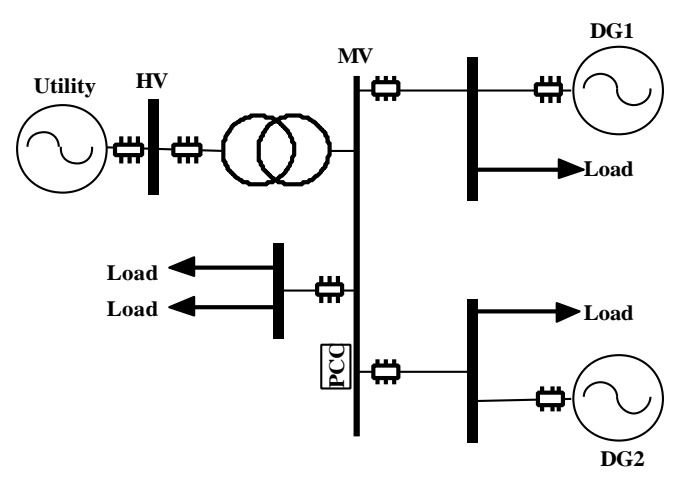

Fig.1: A mini-hydro-wind hybrid system

\subsection{DG1 - MINF-HYDRO}

The DG1 is a mini-hydro generation system, modelled as a synchronous generator, a mechanical hydraulic type of governor and an ac exciter. The governor system of the mini-hydro unit performs two important tasks: ensures a stable islanding operation and responds to load changes [8]. Fig.2 shows the governor control system of a minihydro. The water turbine used for this generation system is a non-elastic water column type, which does not have a surge tank. Setting the governor parameters plays a major role for islanding operation as well as the operation with the grid system. A high transient droop $R_{t}$ and long resetting time $T_{r}$ are usually chosen for a stable and satisfactory islanded system. A low permanent droop $R_{p}$ can ensure parallel operation with the grid. A synchronous machine works as a generator if the torque driving the machine $T_{m}$ is positive. Minihydro turbine produces a required mechanical torque in response to the governor control system for required real power generation [8]. The overexcited mode of the generator produces additional reactive power for the system. Generation of reactive power is controlled by the exciter [7]. 


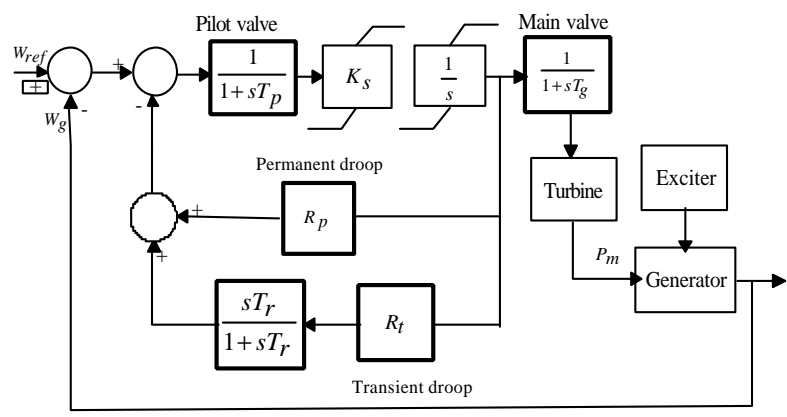

Fig. 2: Mini-Hydro generation system

The main purposes of the exciter are to keep the generator in synchronism with the power system (by supplying required energy to generator's magnetic field), and to supply reactive power during system disturbances [7].

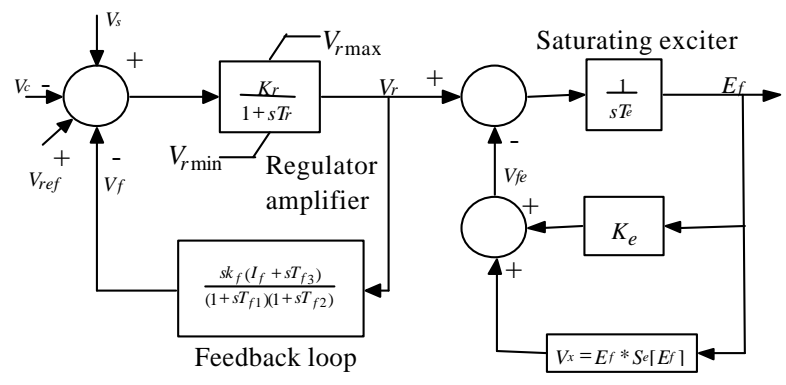

Fig.3: IEEE type AC5A Exciter system [9]

A brushless exciter system defined by IEEE [9] is used in this simulation. Fig. 3 shows a simplified form of the IEEE alternator supplied rectifier excitation system (AC5A). This type of exciter uses the generator terminal voltage and current as references. It has a voltage regulator with a limiter, a damping loop and a saturation function. In this study, the limiter of the voltage regulator is set at a high range to allow maximum control of the system voltage with the maximum reactive power injection for the system.

\subsection{DG2 -WIND TURBINE}

The wind power unit is modelled using an asynchronous generator, a wind turbine, and a wind governor. The wind governor produces controlled pitch angle, which is used as a turbine input. Turbine produces required mechanical torque for asynchronous generator from shaft dynamics, blade dynamics and pitch angle [10]. Fig.4 shows a governor control system of the wind power generation system. The wind generation unit uses a wind turbine of the three-blade type and an induction generator of the squirrel cage type. In this model, a negative mechanical torque makes an induction machine to operate as a generator; the speed of the machine is above synchronous speed. The squirrel cage induction machine normally has two bars: upper bar and lower bar. The upper bar has high resistance and low reactance characteristic, which is suitable for machine starting. The lower bar has low resistance and high reactance characteristics, which ensures better performance in normal operation conditions [10]. Capacitor banks often are employed in the stator of the generator to supply required reactive power in the system.

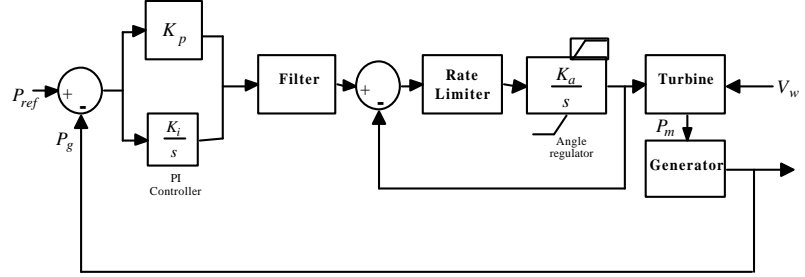

Fig.4: wind generation system

\subsection{LINES AND TRANSFORMERS}

A hybrid system usually supports customers at low and medium voltage levels in a small area, consisting of small generation units, loads and short distribution lines. Thus a model of a short transmission line with R-L equivalent is used to represent the distribution line of the network.

A hybrid system is connected to the grid system using step-up transformers; the three phase two winding transformers are used. The Delta connected to the high voltage side and the star with a neutral to the low voltage side. This kind of arrangement does not alter zero sequence impedance of the grid and reduce $3^{\text {rd }}$ harmonic voltage in the network [12].

\section{DESCRIPTION OF TEST SYSTEM}

A test system is simulated using PSCAD/EMTDC to investigate dynamic behaviour and transient stability of the hybrid system. Three scenarios are considered: the hybrid is connected to the grid, islanding process and the system operation when the island is formed. Fig.5 shows the PSCAD model of the test system, with $110 \mathrm{kV}$ on the $\mathrm{HV}$ side and $11 \mathrm{kV}$ on the MV side. Two transformers $10 \mathrm{MVA}, 110 \mathrm{kV} / 11 \mathrm{kV}$ each are used. The rating of the hydroelectric generator is $5 \mathrm{MVA}$; it is connected to the $11 \mathrm{kV}$ bus. The wind turbine is $2 \mathrm{MVA}$; it is generating power at low level voltage and connected to distribution network through a step-up transformer of 2.5 MVA. The hybrid system has residential, commercial and industrial loads totaling of 5.2 MVA connected to the distribution network.

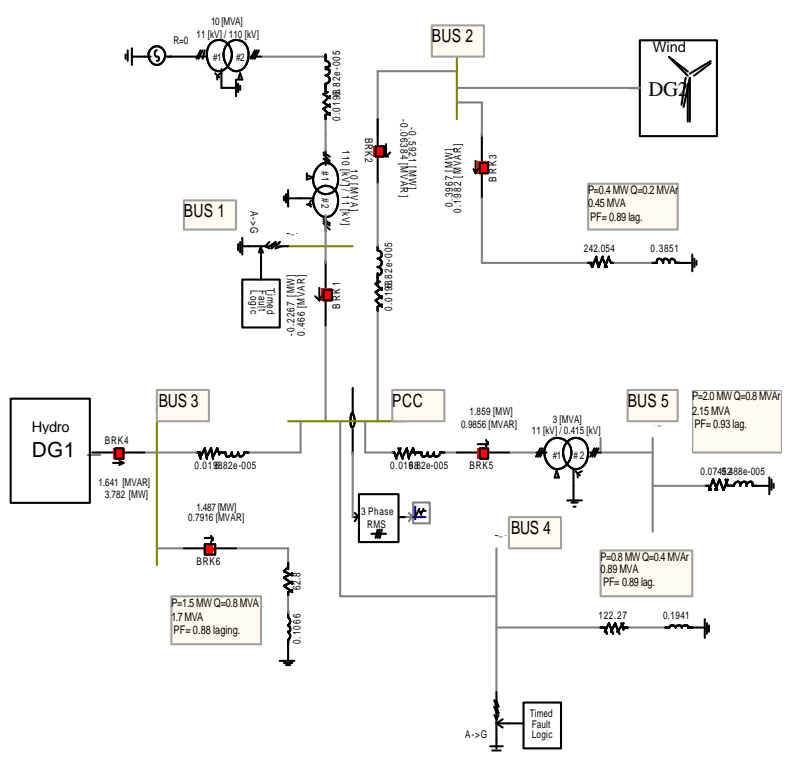

Fig. 5: Test System in PSCAD 


\section{SIMULATION CASES AND RESULTS}

Several cases are examined to investigate the control responses of the hybrid system. Simulation has been carried out for 10 seconds of the time frame when the hybrid system is grid connected, and for 50 seconds when the system is islanded. The system disturbances are modelled in PSCAD as either temporary or permanent faults.

\subsection{GRID CONNECTED HYBRID SYSTEM}

To investigate the dynamic behaviour of a grid connected hybrid system during disturbances, a singleline-to-ground (SLG) fault is modelled employing the PSCAD fault logic. A single-line-to-ground fault occurs on Bus 4 at phase A at time $5.0 \mathrm{~s}$ after simulation start and is sustained for $50 \mathrm{~ms}$. Fig. 6 shows the system response during the fault. The system has returned to the normal operation condition after clearing the fault at 5.05 second. Figs 6(a) and 6(b) show the real and reactive power injection by DG1 and DG2 during the fault. During the fault, real and reactive power injections by DG1 and DG2 have undergone severe oscillations, at which reactive power takes longer settling time than real power. This is due to the fact that the reactance of the system is high, which causes high demand in reactive power [13]. Fig.6(c) shows response of exciter voltage of DG1 during the disturbance. As can be seen the field voltage changes from 1.52 p.u. to 2.01 p.u. The fast change on the field voltage during the fault helps to restore the voltage stability of the system. Figs $6(\mathrm{~d})$ and 6(e) show terminal voltage of DG1 and DG2 at which the voltage dips during the fault are approximately $20 \%$ and $10 \%$, respectively. Figs 6(f) and 6(g) show rotor speed transients of DG1 and DG2 during the fault. It is seen that speed transient of DG1 is less severe than that of DG2. This is because the inertia of the synchronous machine is higher than that of the asynchronous machine.

\subsection{ISLANDING PROCESS}

The second scenario accuiues the occurrence of a permanent three-phase-to-ground fault to observe the DG responses during the islanding process. The fault occurs at Bus 1 at $15.0 \mathrm{~s}$ after the simulation starts. Overcurrent and undervoltage relays respond and send signals to the circuit breaker, which opens at $15.05 \mathrm{~s}$. The hybrid system becomes islanded. The DG response is shown in Fig.7. Figs 7(a) and 7(b) show the real and reactive power injection of the DG1 and the DG2, respectively. Initially the DG1 is exporting real power to the grid. When the system becomes isolated from the grid, the governor system of the DG1 adjusts real power injection from $3.84 \mathrm{MW}$ to $3.62 \mathrm{MW}$ to support the local loads. As the DG2 is an induction generator and has a limitation in producing reactive power, reactive power injection from the DG1 increases from 1.92 MVAr to 2.08 MVAr. Figs 7(c) and 7(d) show transient effects on rotor speeds of the DG1 and the DG2, respectively.

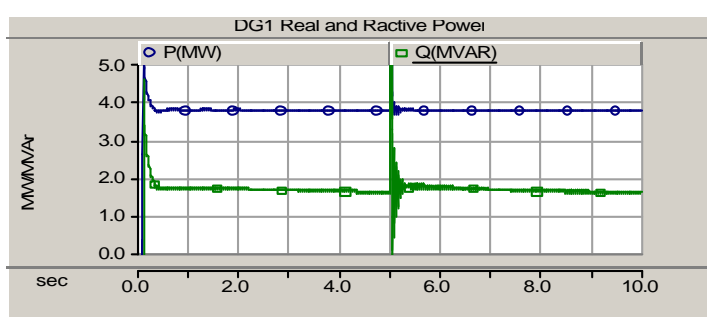

(a): Real and Reactive power of DG1

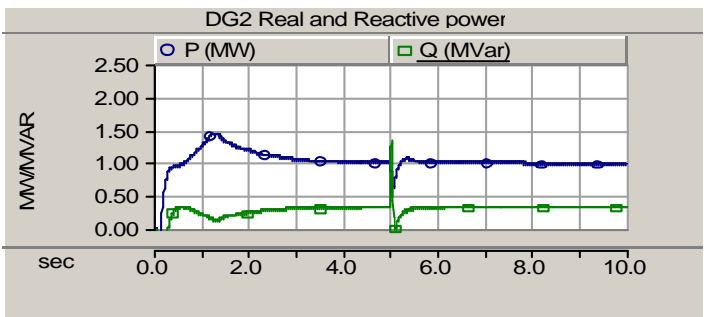

(b): Real and Reactive power of DG2

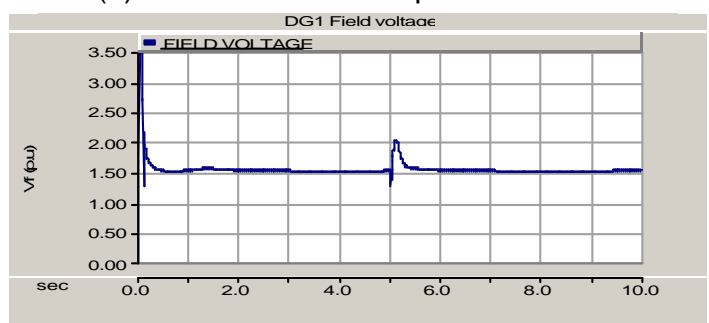

(c): Field voltage of DG1 exciter

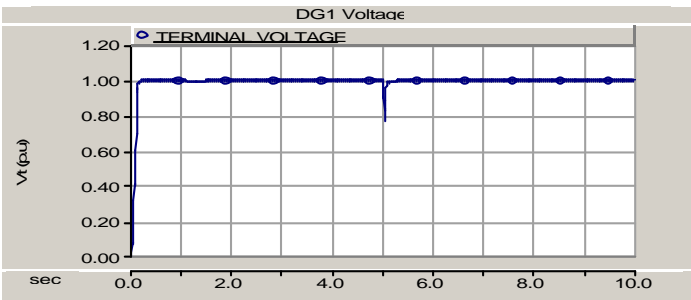

(d): Terminal voltage of DG1

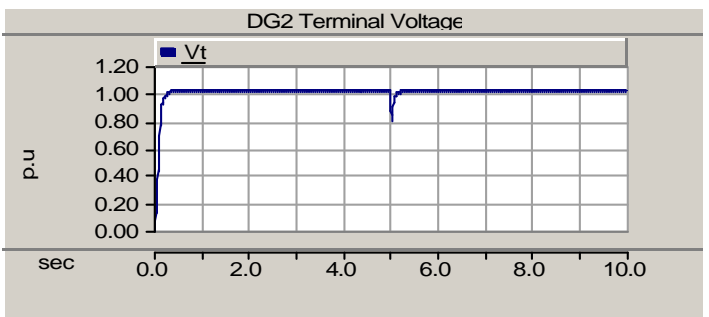

(e): Terminal voltage of DG2

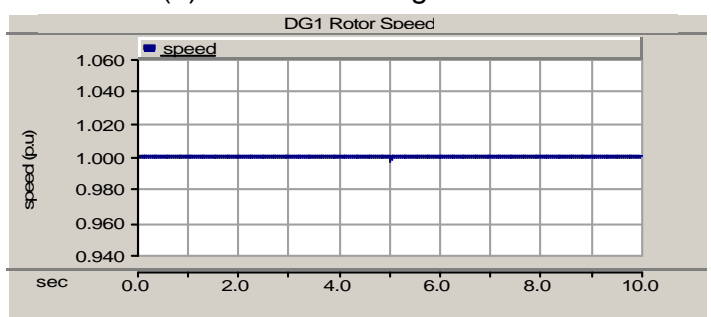

(f): Rotor speed of DG1

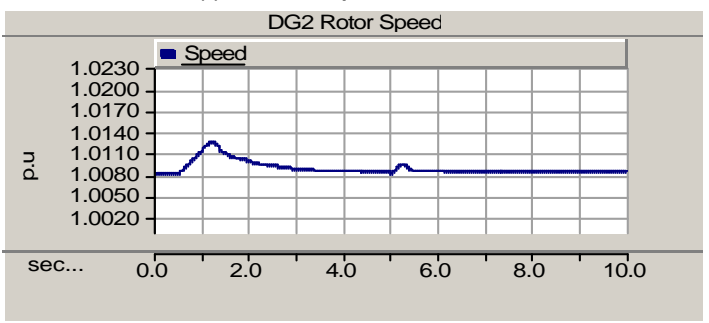

(g): Rotor speed of DG2

Fig.6: DG responses on single line to ground fault 


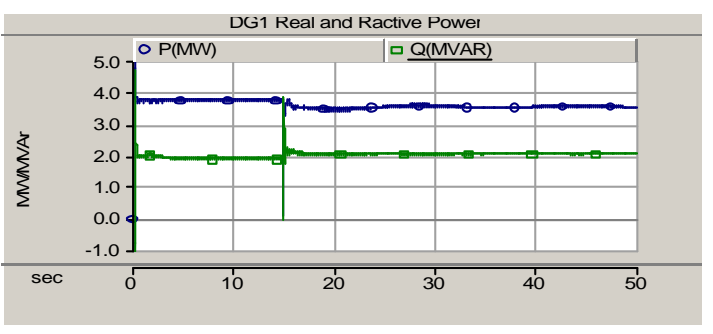

(a): Real and reactive power of DG1

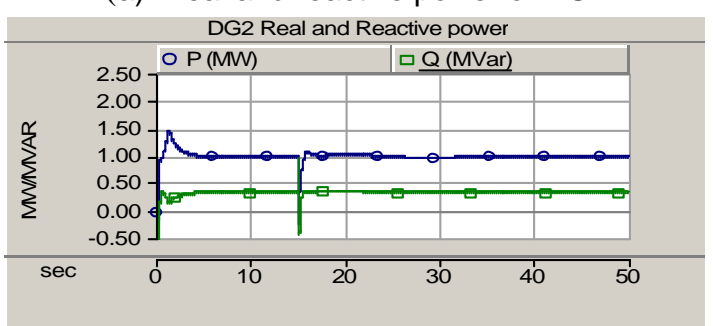

(b): Real and reactive power of DG2

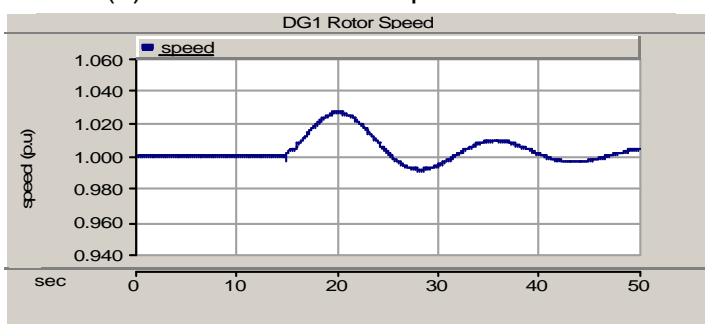

(c): Rotor speed of DG1

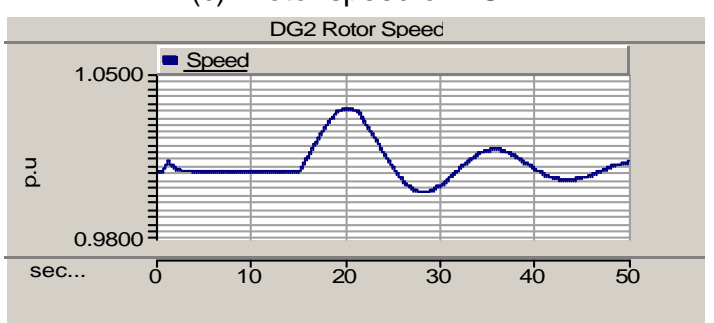

(d): Rotor speed of DG2

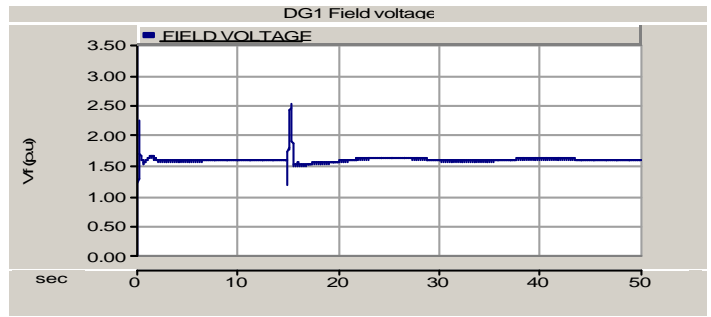

(e): Field voltage of DG1 exciter

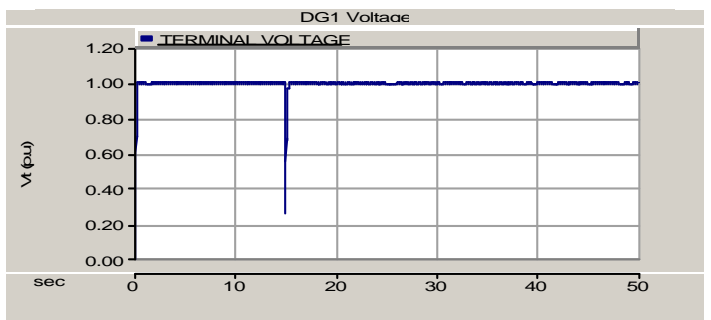

(f): Terminal voltage of DG1

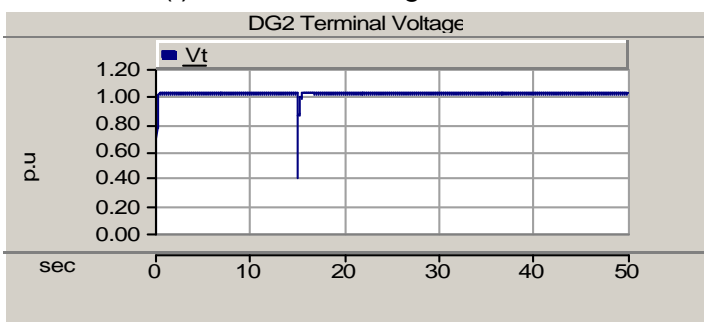

(g): Terminal voltage of DG2

Fig.7: DG responses on during and subsequent to islanding process
Fig.7 (e) shows the field voltage of DG1. The initial field voltage is 1.63 p.u. before the fault; it increases to 2.50 p.u. during the fault and becomes 1.71 p.u. after the fault is cleared. Figs 7(f) and 7(g) show voltage dips at the terminals of the DG1 and the DG2, respectively. The voltage stabilises in a few cycles after the fault. The terminal voltage is restored with the help of the exciter.

\subsection{THE OPERATION OF THE ISLANDED SYSTEM}

To examine dynamic stability of an isolated hybrid system during disturbance, the third scenario with a single-line-to-ground fault is studied. A temporary single-line-to-ground fault occurs for the duration of 40 ms on BUS 4 at $15.0 \mathrm{~s}$ after the simulation starts. The responses of the DG1 and the DG2 are reported in Fig.8. Fig.8(a) shows variations of the real and reactive power injection from the DG1 before, during and after the fault. The response of the DG2 is almost identical to the DG1 but takes more time to stabilise after the fault. This is due to the fact that the synchronous generator responds faster than the asynchronous generator in transient conditions. Fig.8(b) shows the exciter voltage response of DG1. The field voltage increases from 1.61 p.u. to 2.10 p.u.. Figs 8(c) and 8(d) represent transient effects on the rotor speeds of the DG1 and the DG2, respectively. Figs 8(e) and 8(f) show voltage dips at the terminal of the DG1 and the DG2 during the system disturbance. As can be seen from Figs 8(c)-8(f), the voltage restoration process is faster than that of the speed restoration.

\section{CONCLUSIONS}

In this paper, a dynamic behaviour of a simple minihydro/wind hybrid system has been investigated with the use of PSCAD/EMTDC. Dynamics of the hybrid system and the DG responses are examined for the grid connected system, the system operation during the islanding process and the operation of the islanded system. Control parameters have been optimised to operate with the grid and also in the islanding mode. The transient stability has been investigated under temporary and permanent faults. The restoration to the normal operating condition after clearing the fault is faster in the grid connected mode compared to the islanding mode. An appropriate design of the control system is required to ensure the successful operation with the grid as well as the island state. The simulation results have proved that optimal settings of control parameters allows to maintain both voltage and frequency within desired levels during islanding operation.

\section{ACKNOWLEDGEMENTS}

This research has been funded by the Australian Research Council under ARC Linkage Grant K0014223 "Integration of Distributed and Renewable Power Generation into Electricity Grid Systems". The authors also would like to thank Aurora Energy, Tasmania for their support. 


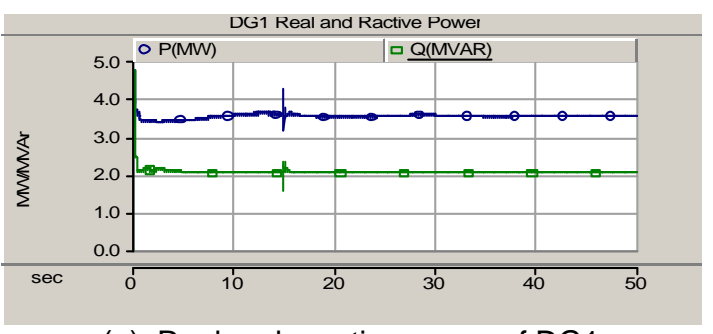

(a): Real and reactive power of DG1

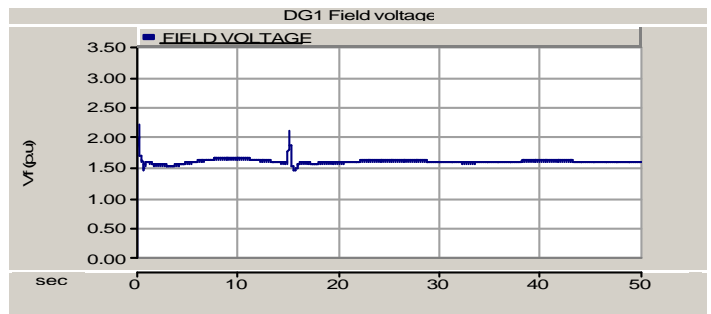

(b): Field voltage of DG1 exciter

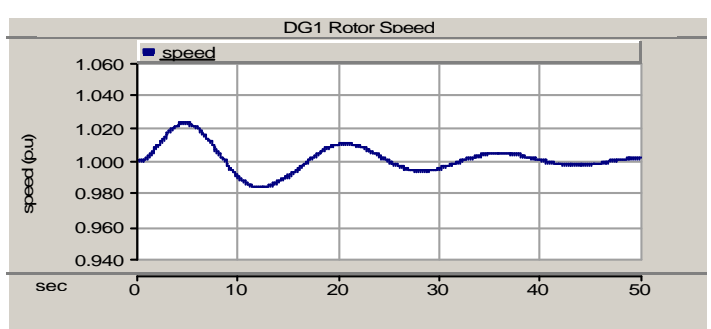

(c): Rotor speed of DG1

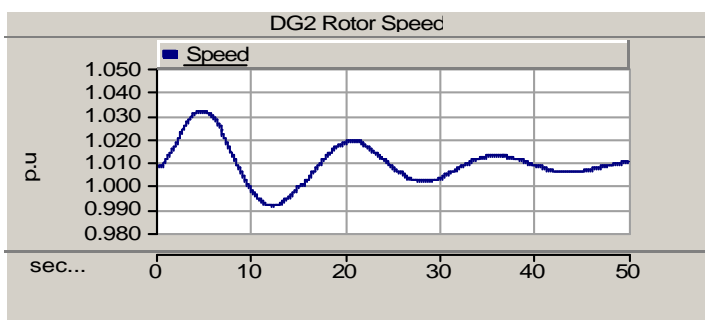

(d): Rotor speed of DG2

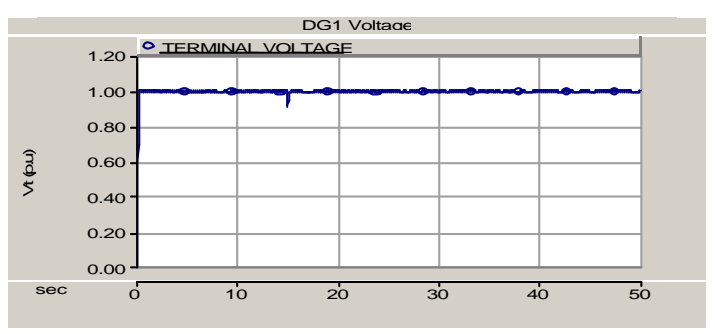

(e): Terminal voltage of DG1

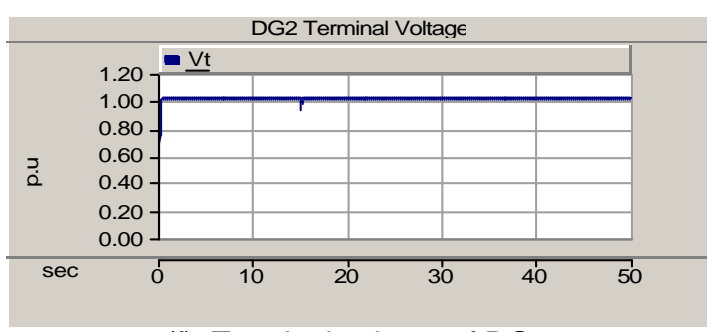

(f): Terminal voltage of DG2

Fig.8: DG responses on islanded system

\section{REFERENCES}

[1] G.M.Masters, "Renewable and efficient electric power systems", IEEE press, WileyInterscience, Hoboken, New Jersey, 2004.
[2] P. P. Barker and R. W. De Mello, "Determining the impact of distributed generation on power systems: Part 1 - Radial Distribution Systems", Proc.of IEEE PES summer meeting, Vol. 3, 2000, pp. 1645-1656.

[4] M.A. Kashem and G. Ledwich, "Anti-islanding protection and islanding operation of gridconnected hydropower distributed generation", Int. Journal of Global Energy Issues, Vol.24, Nos.1/2, 2005, pp.76-85.

[5] R.A. Walling and N.W. Miller, "Distributed generation islanding-implications on power system dynamic performance", Proc. of IEEE PES Summer Meeting, Vol. 1, 2002, pp. 92- 96.

[6] F. Katiraei, M.R. Iravani and P.W. Lehn, "Micro-grid autonomous operation during and subsequent to islanding process", IEEE Transactions on Power Delivery, Vol.20, No.1, 2005, pp. 248-257.

[8] Working Group J6 of the Rotating Machinery Protection Subcommittee, Power System Relaying Committee, "Performance of generator protection during major system disturbances", IEEE Transactions on Power Delivery, Vol.19, No.4, 2004, pp. 1650-1662.

[7] P.Kundur, "Power system stability and control”, New York, McGraw-Hill, 1994.

[9] "IEEE Recommended practice for excitation system models for power system stability studies”, IEEE Std. 421.5-1992,1992.

[10] P.M. Anderson, A. Bose, "Stability simulation of wind turbine systems", IEEE Transactions on Power Apparatus and Systems. Vol. PAS 102, No. 12, 1983, pp. 3791-3795.

[11] PSCAD/EMTDC User's Guide, 2003.

[12] A.G.G. Rodriguez, M.B. Payan and C.I. Mitchell, "PSCAD based simulation of the connection of a wind generator to the network", IEEE Porto Power Tech Conference, 10th $-13^{\text {th }}$ September 2001, Porto, Portugal.

[13] P.M. Anderson, A.A. Fouad, "Power system control and stability", The Iowa State University Press, 1977. 